\title{
Los Libros del Paraíso y del Infierno. Una lectura poética del periplo ultramundano de Dante Alighieri y Charles Baudelaire
}

Leandro Iparraguirre

Universidad Autónoma de Entre Ríos

\author{
cosí dentro una nuvola di fiori \\ che da le mani angelice saliva \\ e ricadeva in giú dentro e di fori \\ sovra candido vel cinta d' uliva \\ donna m' apparve, sotto verde manto \\ vestita di color di fiamma viva \\ E lo spirito mio, che già cotanto \\ Tempo era stato che a la sua presenza \\ non era di stupor, tremando, affranto, \\ sanza de li occhi aver piú conoscenza, \\ per occulta virtú che da lei mosse, \\ d' antico amor sentí la gran potenza \\ Purgatorio XXX, pp. 28-39 ${ }^{1}$
}

Dante Alighieri y Charles Baudelaire emprendieron dos viajes -análogos y divergentes entre sí- por regiones ultramundanas, actualizando las estructuras míticas del periplo del héroe ${ }^{2}$. Ambos itinerarios se constituyeron en arquetipos o alegorías de carácter universal que representaron dos modos de concebir el mundo, la realidad y las relaciones del hombre con el otro. Ambos diseños de arquitectura laberíntica tienen momentos de encuentro, continuidad y cercanía aunque también -y sobre todo-amplias bifurcaciones, proyecciones y metas que conducen a cada uno de los protagonistas a la separación definitiva con el otro y a su propio extravío. Alguien creyó ver en Las Flores del Mal de Baudelaire una continuación de la trama del racconto dantesco, un cuarto viaje de ese recorrido simbólico (Inferno, Purgatorio Paraíso) que culminaría en la descripción de la topografía nebulosa de un París contemplado desde la óptica del spleen y la desidia más absoluta ${ }^{3}$. En ambos casos los poetas irán construyendo una imagen femenina disímil, ambos van tras la sombra de una mujer inaprensible y eternamente ausente que se vislumbra fugazmente y se diluye a través de la memoria y la escritura. Nosotros los lectores seguiremos apenas los vestigios de ese rastro difuso.

Para Dante atrás quedó el Infierno tan temido, esa tierra de llantos y dientes crujientes, también tras de sus pasos fueron quedando las culpas, los signos en la frente y ese monte que Ulises divisó tan lejano antes de su caída. Dante Alighieri ya no se encuentra extraviado en esa selva selvaggia, áspera y fuerte que en su pensamiento renovava su pavura. Atrás quedó el espanto y el oprobio del fuego que todo 
lo consume, los hombres condenados, las bestias inhumanas de apariencia biforme. Este impávido viajero de regiones ultramundanas (abismales y metafísicas) ingresa ahora aliviado sin el peso del estigma del pecado y sin la fragilidad de una conciencia que se sabe culpable, en una selva de luz inusitada que despliega por doquier un esplendor y una magnificencia tales que enaltecen y purifican su cuerpo y su alma íntegramente: es el Paraíso Terrenal, ese Edén primigenio perdido de manera inexorable en la memoria de los hombres. El espíritu apaciguado del poeta no siente más temores ni tampoco pesares e ingresa en esa nueva etapa de un itinerario del que regresará transfigurado, como un extranjero frente a un mundo inaudito, jamás imaginado: "Deseoso de explorar dentro y en torno / la Divina Floresta espesa y viva, / que a mis ojos templaba el nuevo día" [Purgatorio XXVIII: pp. 1-3] escribirá absorto. Dante caminará expectante y sin prisa contemplando esas primicias de una tierra, virginal e inefable, que anticipa y anuncia ese otro Paraíso con el que ha soñado tantas veces en eternas vigilias y en anhelos insomnes desde la muerte de Beatriz. Virgilio está a su lado todavía:

En tierras sin verdor, de ceniza y de lava,

mientras yo me quejaba un día a la Natura,

y de mi pensamiento, vagando a la ventura,

lento en mi corazón el puñal aguzaba,

vi en pleno mediodía bajar sobre mi frente

una fúnebre nube de tormenta inminente,

que portaba un rebaño de demonios viciosos,

semejantes a enanos crueles y curiosos.

Pusiéronse a mirarme entonces fríamente,

y como de algún loco que pasa habla la gente,

los escuché entre sí reír y cuchichear,

y más de un guiño y más de una seña cambiar ${ }^{4}$

Charles Baudelaire ha ingresado abruptamente en una obscura y salvaje región y apenas ha comenzado su extravío, cuando efluvios y miasmas nauseabundos le anuncian un destino. El poeta recorre - displicencia y hastiado- espacios abismales iluminados con una luz opaca de ceniza y de lava, en un mundo de sombras sin verdor, ni esperanza. Es la vida esa selva selvaggia, umbría, insoportable, espesa, laberíntica de la que nadie salió vivo. Baudelaire vagando a la ventura es un flaneur a la deriva que no encontrará un sitio en esta tierra en donde descansar, ni un hogar en donde depositar su cabeza y apaciguar su espíritu. Es un viajero que transita un camino indecible, sin un hilo de Ariadna que conduzca hacia el centro, sin un vestigio que anticipe la fuga o pueda improvisar una salida. Un extranjero errante que mientras más se pierde más se encuentra y cuanto más desciende, cornisa tras cornisa, a los recónditos rincones (a lo más abyecto) de su alma, más verdadera, fiel y humana será la imagen de su rostro. Su experiencia vital es un desesperado, eterno y angustiante camino hacia la soledad y hacia la muerte ${ }^{5}$. Todos los poetas románticos han hablado de ese Dios que es esencia y trascendencia de lo humano y él sólo lo conoce indirectamente a través de los relatos de testigos poco fiables y a partir del dolor subsiguiente al pecado o el goce irreverente en la blasfemia y en la transgresión.

Baudelaire es un viajero inmerso en una travesía inverosímil que recorre las calles de una topografía sin sentido (cruel y absurda) mientras su pensamiento va imaginando nuevos crímenes; su carne, recordando placeres clandestinos; y su boca, quejándose de la Naturaleza, de ese incierto designio de vivir sin desearlo. El Mal, el demonio inevitable de la perversidad, ese íncubo que se sienta en nuestro pecho y nos susurra en un insomne hechizo, pecados innombrables que subyugan al cuerpo, es su compañía, su guía en el descenso. Él cree que es preferible descender a los 
más profundos y bestiales círculos de la ciudad de DITE antes que transitar por siempre las periferias del infierno dantesco con el cinismo de los hipócritas o la pasividad de los ignavi. Es la Naturaleza la que arrastra al poeta a infames territorios, quien pervierte sus actos, la que opaca sus cielos. Es el Tedio inaudito ese monstruo sediento de sangre que devora y consume su vida (y la de tantos) como un perro insaciable, un Cancerbero infame Es el Tedio -que nos fascina y nos degrada y es Satán quien maneja los hilos que nos mueven.

El Mal insoslayable que rige los ocultos mecanismos de este mundo y exalta las más siniestras y degradantes pasiones es el que lo sostiene orgulloso y altivo. Su espíritu, incrédulo y absorto se vuelve a incorporar intacto detrás de las caídas de su cuerpo. Baudelaire se siente pecador, se sabe corrompido y permanece incólume. Sabe que el poeta se eleva con alas gigantescas como un ave marina que vuela brevemente y siempre a ras del suelo ${ }^{6}$. Más allá de ese sol oculto en un eclipse, entre nieblas y brumas, transfigurado en ébano (silencioso y distante) una luz más perfecta, resplandeciente y clara, constante en su memoria, límpida en su conciencia, es la que lo sostiene todavía. No necesita verla para saber que existe, ilumina su esencia como un faro distante que guía a los navíos en una noche negra y tempestuosa. Él camina entre sombras sintiendo la nostalgia de esa luz de un Paraíso que alguna vez fue suyo y aún persiste. El viajero vislumbra los mares infinitos con corazón de niño -escribe Baudelaire- todo es tan novedoso que parece posible: un secreto Universo desplegado frente a nuestra mirada, un planisferio sin medidas o un diario de bitácora de interminables páginas y siempre ese mítico mar -primigenio y arcaico- siempre incesante, siempre comenzando que nos impulsa al viaje ${ }^{7}$. El alma es un navío que emprenderá su ruta por mares insondables -la vida y sus escollos- en búsqueda de un sitio al que denominar su patria, como lo hiciera Ulises tan lejos de su casa. El alma es un viajero que siente la nostalgia indecible de lo que nunca tuvo, de lo que no fue suyo. ¿Qué importan los infiernos?, murmurará en voz baja el poeta maldito, el amor, el oprobio, los placeres, los vicios, la fama, el dolor y el hastío, son escollos del alma, simulacros absurdos, bifurcaciones del camino que dificultan la llegada hasta un puerto seguro. El Paraíso verdadero está adelante, siempre adelante, nos alienta el vigía, aunque se esconda en la memoria o aunque parezca un imposible. No detenernos nunca aunque el sol esté oculto, aunque la ausencia y el silencio de un Dios de Bondad Infinita, enmudezca nuestra alma, aunque el infierno nos parezca insalvable. Ese Periplo que Dante Alighieri nos proponía se iniciará tras nuestra muerte. Nuestra vida terrenal adquiere su sentido verdadero en la esperanza de ese sitio ultramundano en donde todo dolor $y$ pesar serán solo vestigios sin memoria. El viaje de Baudelaire, en cambio, culmina con la muerte, no existen para él redención, ni trascendencia más allá de esta vida. La existencia del hombre es nada más que un transitar por innumerables infiernos cotidianos hacia lo incognoscible mientras imaginamos que existe un Paraíso. En ambos casos el Paraíso esta adelante, siempre adelante, nos alienta el vigía en el mar proceloso... Dante estuvo en él, Baudelaire lo imagina.

Guardaci ben! Ben son, ben son Beatrice.

Come degnasti d' accedere al monte?

Non sapei tu che qui è l' uom felice?

Li occhi mi cadder giú nel chiaro fonte;

Ma veggendomi in esso, $\mathrm{i}$ trassi a l' erba,

Tanta vergogna mi gravò la fronte.

Purgatorio XXX, pp. $73-78^{8}$ 
A través de esa Divina Floresta que Dante Alighieri transita se expande una luz inefable, como la de un relámpago que ilumina los cielos y, sin embargo, el fulgor de un relámpago dura sólo un instante, en cambio, esa luz permanece y se instala en su alma como si fuese su morada. Desde el Oriente esa sublime luminosidad viene a su encuentro, como un crepúsculo de fuego que torna el aire denso, que vuelve diáfano el paisaje y más traslúcidos a los seres que lo habitan. Al mismo tiempo, una sutil y dulce melodía que invadía el espacio va transformándose en un clarísimo y distinto canto, como el anuncio de una epifanía [Purgatorio XXIX: pp. 34-36]. Todos esos signos anticiparán la procesión triunfal con la cual alegórica y beatíficamente se presenta su amada ante su vista. Una visión anticipada de siete candelabros, como árboles de oro, inicia la procesión de voces que entonan alabanzas y que cantan Hosannas, detrás vendrá la magnificencia indescriptible de ese carro conducido por un Grifo mayestático. Metafóricamente el triunfo de la Iglesia y Cristo, su cabeza, con su naturaleza dual, encarnación humana y substancia divina y detrás, todavía, la efigie de Beatriz transfigurada.

A través de una vorágine de flores y de criaturas angélicas surge -como si fuera un simulacro o una mixtificación una mujer velada, altiva, inalcanzable-. La acompañan ancianos con blancas vestiduras y vírgenes sin mácula que expresan un éxtasis infinito. Primero el estupor y el pasmo del poeta. Después la secreta intuición de haberla conocido. Detrás del velo cándido que a encubierto su rostro Dante ha vislumbrado a una mujer que amó con pasión infinita. Es ese mismo amor, el idéntico fuego, el que arde en su pecho en un instante y lo consume. Esa mujer velada -angelical, redentora, beatífica- es la transubstanciación del amor divino, del primo movile que muove al Sol e l' altre stelle [Paraíso XXX, p. 145]. Una mujer que fue como una sombra en encuentros azarosos en calles florentinas y que ahora se yergue frente a él, inaccesible como una eterna esfinge. Desde hace mucho tiempo Dante no sentía ese estremecimiento. Ante esa visión severísima y distante de una mujer incognoscible y al mismo tiempo presentida el poeta cierra los ojos mientras su cuerpo laxo y su espíritu perplejo, se acurrucan, como un niño, dentro de un sueño diurno, íntimo y antiquísimo, en el que ve a Beatriz como nunca la viera: transfigurada en la persona de Francesca, cual si fueses una diosa pagana o una mujer posible. Dante probablemente recordó aquel logos tres veces reiterado en el segundo círculo en los labios de esa amada: amor que prontamente anida en corazón gentil, amor que no consiente que no amemos, amor que nos arrastró conjuntamente hacia la condenación y hacia la muerte. Dante quiere saber, revelar ese enigma, descubrir por cuál causa aquel amor gentil cayó en el extravío. Una frase del racconto de ella pervive en su memoria y se aproxima a la clave del misterio: "questi, che mai da me non fia diviso" [Infierno V, 135]. Dulce condenación, suave extravío que a las almas amantes confunde y unifica en una sola alma y en un solo castigo. Dante Alighieri enmudecido y vulnerable, gira el rostro indeciso y descubre que Virgilio no se encuentra a su lado. La imagen de Beatriz altiva e impiadosa pronunciará su nombre, lo hará por vez primera y por postrera vez para que Dante sienta, para que Dante sepa que no es su Beatriz, aunque nunca fue suya.

Contemplemos a gusto esta caricatura,

esta sombra de Hamlet que imita su postura,

los cabellos al viento, la mirada indecisa.

¿No es cierto que da lástima y también mueve a risa

ver a este vago, histrión, sin teatro, vividor,

que porque representa su parte con calor

pretende interesar cantando sus dolores

al águila, al grillo, al arroyo y las flores, 
y hasta a nosotros, padres de esas viejas chuscadas

a gritos nos recita en públicas tiradas? ${ }^{9}$

Baudelaire inicia su arduo camino hacia el madero de tormento en el mismo instante de nacer, como un siervo ignominioso de un Dios desconocido. La maldición materna, el desamor femenino, el repudio de sus contemporáneos, el silencio de Dios lo acompañarán, como lo hizo el demonio con Cristo en el desierto. Su corazón tan frágil, tan humano y su naturaleza transgresora no creen en milagros y él se encuentra escindido entre servir a dos amos disímiles: uno le ha prometido placeres indecibles, otro le ha anticipado un Paraíso ultraterreno. Baudelaire cree que si la vida de él y la de tantos proscriptos, marginados y maldecidos no es más que un transitar errante sin detenerse nunca por los infiernos de la tierra ¿de qué sirve el asombro?, ¿para qué la esperanza? Todo lo que vendrá, todo lo que encontremos en este peregrinar por los confines de la tierra debe ser espantoso.

Hubiera yo podido (alto como los montes

es mi orgullo y domina demonios y horizontes)

apartar simplemente mi cabeza serena

si no hubiera mirado entre su tropa obscena

iy este crimen no hizo al sol tambalear!

a la reina de mi alma, de mirada sin par,

que de mi desamparo con ellos se reía,

y a veces cualquier sucia caricia les hacia. ${ }^{10}$

Los demonios se ríen de ese orgullo malsano, lo creen impostura, falsedad, simulacro. Contemplemos susurran entre sí, a este personaje que imita la postura de Hamlet: dubitativo, inútil, abstraído del mundo, siempre tras de una sombra que parece distante, sin atreverse nunca a guardar en ese estuche blando, sangrante y frágil que esconde tras el pecho, el puñal que han forjado pensamientos inciertos". Como un histrión nos miente y pretende engañarnos, es un actor sin proscenio que imita la locura de Hamlet, el delirio de Lear y reitera un discurso tan vacío y tan hueco, como su propia existencia, un discurso repleto de sonido y de furia, de nihilismo absoluto, que nada significa. Nosotros, expertos hacedores de falsías, no podemos creerle, es tan sólo un artista y es todo un simulacro. Ha cubierto su rostro con ceniza, ha ocultado su faz tras una máscara de tedio y de melancolía, sus oscuros ropajes son (también) un pretexto. El dolor no se cubre de apariencias, ni se viste con ropajes externos de duelo ¿No ven cómo está parodiando los rasgos y los gestos de un poeta romántico: sus cabellos al viento, su mirada indecisa? Ahora transita las cornisas e irregularidades del Infierno como si fuese un mártir, un hombre atormentado por un amor perdido irremediablemente. Como si no supiera que su alma está predestinada a la condena y que pertenece desde siempre a este ámbito. Quiere hacernos creer que su espíritu es evanescente fragancia que se disuelve sutilmente y no el aroma inmundo y corrompido del Bien que se degrada, como lo hace un cadáver en lo profundo de una fosa. Su alma se ha cubierto de costras y de mugre, de llagas y de úlceras, como la carne de un leproso. Si es uno de los nuestros, si conoce al demonio como nosotros mismos, si es el discípulo dilecto, compañero y sirviente de Satán Trismegisto y en la almohada del Mal apoya su cabeza. Debes saber, hipócrita viajero que te asombra esa muerte y te angustias y quejas indecorosamente, que es natural que muera lo que hemos amado o hemos creído amar. No es natural -en cambio- transformar ese duelo en cruel melancolía, en eterno desdén o en odio exacerbado. Ni tampoco es real que ese amor nos arrastre hacia una fosa inmunda, que nos quite el aliento, que nos vacíe el alma... Si en verdad eres Hamlet, vete detrás de Ofelia que aún yace extasiada en la muerte, tendida sobre el agua, sus ropas empapadas la empujan hacía el fondo de ese abismo, su mirar constelado y su 
espíritu apacible la devuelven a un cielo que le fuera negado. Fue su amor su delito, amar a aquél que no debía y aún sigue adorándote en ese lecho de aguas -reflejo de tu desamor- en el que fue a mirarse. ¿ Si tanto la amabas por qué sigues con vida y aún tienes el puñal estéril entre tus manos? Si no la amaste, miente tu apariencia. Si la amas todavía y estás vivo ¿para qué haberla amado?

Contemplemos -anuncian en voz alta los demonios-a este histrión que simula un dolor que tan sólo imagina, un amor que nunca fuera suyo ¿̨Qué importa si está muerta si en tu corazón, sigue ardiendo un deseo tan vivo y tan eterno, que es fuego incombustible que no perece nunca, que no tiene un objeto definido y va a seguir ardiendo aunque no estés con vida? Es lógico y humano aferrarse a la vida, como hace el que agoniza en su lecho de muerte aferrado a las sábanas, ver morir a los otros y alegrarnos nosotros de aún seguir viviendo. Si te atreves detrás nuestro (le dicen los demonios) podrás mirar transfigurada a esa mujer que alguna vez fue tuya. Si no tienes valor, si toda tu actitud no es simulacro, vuelve tras de tus pasos, gira atrás la cabeza, regresa a tus dominios. Si amaste no sólo lo que era sino también aquello que ella pudo ser y aún es en su sepulcro, vuelve a ese cementerio en una negra noche, camina entre las tumbas en la imprecisa oscuridad, reconoce su fosa, cava en la tierra húmeda, remueve los escombros, destroza con las manos la podrida madera que te oculta su rostro, superando la náusea y el asco, arranca los vendajes mortuorios que la cubren, acaricia en tus manos esos senos tan tibios que se volvieron pútridos, su carne palpitante, su pubis putrefacto, reconoce en ese rostro, pálido carcomido, a esa mujer amada, deposita tus labios sobre su boca inerme con un beso profundo. A pesar de su orgullo, de su soberbia altiva Baudelaire lo presiente, lo intuye, lo sabía desde siempre, desde el inicio de su viaje. Detrás de los enanos deformes y demonios, entre esa multitud degradada y obscena, que parecen cubrirla como un velo, vislumbra esa belleza insomne, su corazón satánico, sus pechos lujuriosos, su mirar despiadado y la observa pasear su desnudez, sin pudor, sin escándalos. Y ese crimen no hizo sacudir los cimientos de ese indeseable mundo. Baudelaire lo sabía (el demonio lo dijo) no debemos amar a un impreciso objeto que alguna vez creímos que nos pertenecía y que se ha transformado en un difuso vestigio perdido en la memoria. El amor es un hábito que también se desgasta. Hay que amar lo inconstante, lo fatal, lo inaudito. Hay que amar ese cadáver pútrido, inverosímil, que permanece vivo (y aun multiplicado) en un millar de cresas que nacen y se acumulan en la carne en descomposición. Hay que amar esa vida que surge de la nada y aún mantiene intacta esa fuerza vital inexorablemente, con un amor constante más allá de la muerte y de la vida. Hay que amar esa vida que crece y que se expande a pesar del espanto. También somos nosotros esa materia inerme (pletórica de vidas) y aún conserva la esencia (a pesar de su aspecto) de lo que hemos sido y somos todavía.

Existe otro descenso a los infiernos y otra visión particular de esas regiones, que complementa y abarca -al mismo tiempo- los periplos y las visiones de Dante y Baudelaire. Es la singular e inefable contemplación de El Aleph del protagonista principal de ese cuento de Jorge Luis Borges, en un sótano de la calle Garay de Buenos Aires. En esa visión totalizadora y trascendente confluyen y se complementan las dos imágenes anteriores. Beatriz Viterbo, la amada de Borges, es la mujer angelical, idealizada, inalterable y es, al mismo tiempo, -sin que exista contradicción y en perfecta convivencia de opuestos- la Beatriz degradada, subsumida en la carnalidad, obscena y vulgar de Baudelaire. En la visión aléphica borgeana vemos al descubierto, (transparente y translúcido) el verdadero mecanismo descarnado del amor y las modificaciones que produce la muerte sobre aquello que alguna vez amamos y, además y sobre todo, el inefable Universo, como un objeto secreto y 
conjetural donde todas las visiones coexisten, sin oponerse ni anularse en absoluta connivencia como deseaba Heráclito ${ }^{11}$. Paraísos e Infiernos, al fin se sintetizan en una contemplación única y abarcadora. La Beatriz vislumbrada en lo profundo del Aleph, será angelical y demoníaca simultáneamente, será todas las mujeres y ninguna, más cercana a nosotros y también más distante, más verdadera y más real y (por lo tanto) más incognoscible e indescifrable. Como el infinito Universo.

\section{Notas}

${ }^{1}$ Alighieri, D.: La Divina Comedia. Purgatorio Texto original italiano con traducción, comentarios y notas de Angel J. Battistessa. Asociación Dante Alighieri. Buenos Aires. 2003. "...tal al través de nube hacha de flores / que de manos angélicas subia / y recaía luego adentro, afueral sobre cándido velo, orla de olivo, I dama me apareció, tras verde manto / vestida de color de llama viva / Y mi espiritu, que por largo tiempo / no habia estado ante su presencia / de estupor, y temblando, quebrantado, / sin que los ojos me la revelasen, / por oculta virtud que ella irradiaba / de antiguo amor sentí la gran potencia" Purgatorio XXX, pp. 28-39.

${ }^{2}$ Cambell, J.: El héroe de las mil caras. Fondo de Cultura Económica. 1980 y Villegas, Juan: La estructura mítica del héroe en la novela del siglo XX. Editorial Planeta. Barcelona. 1973.

${ }^{3}$ Crolla, A. y Manavella de Fernández, Z.: "La Beatriz": Una AntiBeatriz. Dante en Baudelaire. Actas Terceras Jornadas de Literatura Francesa, Córdoba, 1993. En nuestro trabajo hemos tenido en consideración este trabajo en algunas consideraciones teóricas aunque nuestro abordaje y desarrollo de la problemática femenina en Dante y Baudelaire sea esencialmente diferente.

${ }^{4}$ Baudelaire, Ch.: Las Flores del Mal, "La beatriz", traducción Nydia Lamarque. Losada. Buenos Aires. Argentina. 1996.

${ }^{5}$ Baudelaire, Ch. ob. cit. "Al lector".

${ }^{6}$ Baudelaire, Ch. ob. cit. "El albatros".

${ }^{7}$ Baudelatre, Ch. ob. cit. "El viaje".

${ }^{8}$ Alighieri, D.: La Divina Comedia. ob. cit.

${ }^{9}$ Baudelaire, Сн.: Las Flores del Mal, "La Beatriz", versos 13-22.

${ }^{10}$ Ibidem.

${ }^{11}$ Heráclito, "Fragmentos" introducción, traducción y notas Fernando Demaría. Universidad Nacional del Litoral. Facultad de Filosofía y Ciencias de la Educación. Instituto de Lenguas Clásicas. Rosario. República Argentina. 1957. 